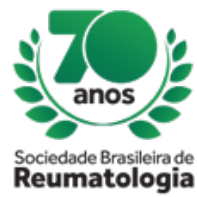

\title{
COUNSELING FOR PATIENTS WITH ANKYLOSING SPONDYLITIS AND THE EFFECTS ON SEDENTARY BEHAVIOR AND QUALITY OF LIFE: A RANDOMIZED CONTROLED TRIAL
}

Alessandro Holanda (UFPE, Recife, PE, Brasil), Bruna Oliveira (UFPE, Recife, PE, Brasil), Alana Veras (UFPE, Recife, PE, Brasil), Paulo Carvalho (UFPE, Recife, PE, Brasil), Roberto Silva (UFPE, Recife, PE, Brasil), Paulo Silva (UFPE, Recife, PE, Brasil), Andre Costa (UFPE, Recife, PE, Brasil), Nara Cavalcanti (UFPE, Recife, PE, Brasil), Angela Duarte (UFPE, Recife, PE, Brasil), Claudia Marques (UFPE, Recife, PE, Brasil)

\section{BACKGROUND}

Sedentary behavior (SB) have been recognized over the past years as a public health issue, since evidence shows its association with several deleterious health outcomes independent of physical activity (PA) levels. Due the ankylosing spondylitis (AS) clinical manifestations, like pain and stiffness, the practice of physical activity among these patients is often compromised, which results in reduced aerobic capacity and physical fitness and consequently SB and low levels of PA. We evaluate the effectiveness of the intervention by counseling in the change SB and in the lifestyle of adults with AS and the effects over disease activity and quality of life.

\section{MATERIALS AND METHODS}

This randomized, evaluator-blind, controlled clinical trial of a 10-week non-pharmacological intervention. Inclusion criteria: AS diagnosis (modified New York criteria); age between 18-59 years. The total sample size of 35 subjects was randomly allocated into 3 groups: COG - counseling group; EXG -exercise group; and CG - control group. Primary outcome: reduction of the SB, measured by International Physical Activity Questionnaire (IPAQ) (minutes/day). Secondary outcomes: physical activity level, Behavior Change Stages (BSC) and quality of life (ASQoL). Subjects in the COG group participated in a 10-session counseling intervention, directed towards health promotion and health education and encouraged to practice physical activity and to set weekly goals to reduce SB. Exercise intervention for the EXG volunteers consisted of a 50-minute session, two days per week, for 10 weeks. Counseling and exercise interventions were conducted during the same period. Data were analyzed through intention-to-treat analysis and effect size measurements.

\section{RESULTS}

The mean age was $41,70(10,48)$ years; $62,9 \%$ were male. It was observed a significant improvement on SB with a reduction of 377 minutes/day to 327 minutes/day in the COG group $(p=0,041)$, and of 405 to 347 minutes/day in the EXG group $(p=0,045)$ after 10 weeks. There was no significant difference in the CG group (Figure 1). There was a significant improvement in ASQoL in COG $(p=0.029)$ and EXG $(p=0.003)$. A positive evolution was observed in the stages of behavior change. The relative risk (RR) to increase physical activity on both interventions groups was 2.44 .

Figure 1 - Sedentary behavior (pre and post intervention) in counseling, exercise and control groups in patients with ankylosing spondylitis ( $\mathrm{Cl}=95 \%)$

\section{CONCLUSION}

Counseling is effective in changing sedentary behavior in adults with AS. Exercise and counseling promote improved behavioral stage, increased physical activity, reduced physical inactivity and improved quality of life. 